\title{
KESEDIAAN MENERIMA PEMBAYARAN JASA LINGKUNGAN AIR SUB DAS WAY BETUNG HULU OLEH MASYARAKAT KAWASAN HUTAN REGISTER 19 (STUDI KASUS DI DESA TALANG MULYA KECAMATAN PADANG CERMIN KABUPATEN PESAWARAN)
}

\section{(WILLINGNESS TO ACCEPT PAYMENT FOR ENVIRONMENTAL SERVICE OF WATER SUB DAS WAY BETUNG UPSTREAM BY SOCIETY FOREST AREA REGISTER 19 (CASE STUDY IN TALANG MULYA VILLAGE DISTRICT OF PADANG CERMIN SUB PROVINCE PESAWARAN)}

\author{
Faisal Arafat, Christine Wulandari dan Rommy Qurniati \\ Jurusan Kehutanan, Fakultas Pertanian, Universitas Lampung \\ Jln. Prof. Dr. Soemantri Brojonegoro No. 1 Gedung Meneng, Bandar Lampung \\ Email: faisalarafat21@yahoo.com
}

\begin{abstract}
ABSTRAK
Salah satu solusi guna mengatasi kerusakan fungsi hidrologi DAS Way Betung adalah penerapan Pembayaran Jasa Lingkungan (PJL) untuk kegiatan rehabilitasi hutan dan lahan. Penerapan PJL perlu dikaji lebih mendalam khususnya mengenai besarnya nilai kesediaan menerima pembayaran oleh masyarakat sebagai penyedia jasa lingkungan. Tujuan penelitian ini adalah mengetahui nilai kesediaan menerima (WTA) masyarakat terhadap PJL Sub DAS Way Betung Hulu dan faktor-faktor yang mempengaruhinya serta mengetahui bentuk-bentuk insentif yang diinginkan masyarakat. Metode yang digunakan dalam penelitian ini adalah analisis Willingness to Accept (WTA), analisis regresi dan analisis deskriptif kualitatif. Berdasarkan hasil analisis diperoleh nilai dugaan rataan WTA responden di lokasi penelitian adalah Rp 8.552,63 per pohon per tahun. Apabila jumlah pohon dikebun campuran masyarakat sebanyak 1.462 pohon maka diperoleh nilai total WTA Desa Talang Mulya adalah sebesar Rp 12.503.945,06 per tahun. Faktor-faktor yang berpengaruh nyata terhadap nilai WTA adalah tingkat pendidikan, umur dan status garapan lahan. Bentuk-bentuk insentif yang diinginkan responden adalah berupa uang tunai, pembangunan pedesaan, bantuan bibit dan pupuk dan hewan ternak.
\end{abstract}

Kata kunci : pembayaran jasa lingkungan, WTA, DAS Way Betung

\section{ABSTRACT}

One of the solution utilize to overcome damage of DAS Way Betung hydrology function is apply of Payment for Environmental Service (PES) for forest and land rehabilitation. PES is needs to be studied more in depth, especially the level of value willingness to accept payment by people as environmental service provider. The purposes of this research are knowing value of willingness to accept (WTA) the people regarding PES of upstream Sub DAS Way Betung and factors to influence it with knowing incentive forms who wanted by the people. Method used in this research are Willingness to Accept analysis, regression analysis and descriptive analysis qualitative. Based on the result, the average of WTA respondent in the location of research is $R p 8.552,63$ per tree per year. If the number of trees in the mix community garden is 1.462 trees, then it will be obtained the total value of WTA Talang Mulya village is Rp 12.503.945,06 per year. Factors which significant influenced to WTA value that are level education, age and status of arable land. Incentive forms who wanted by 
respondent are cash money, rural development, seedlings and fertilizer donations and also farm animal.

Keywords: payment for environmental service, WTA, DAS Way Betung

\section{PENDAHULUAN}

Berdasarkan Peraturan Pemerintah Nomor 3 Tahun 2008 tentang tata hutan dan penyusunan rencana pengelolaan hutan serta pemanfaatan hutan, pemanfaatan jasa lingkungan adalah kegiatan untuk memanfaatkan potensi jasa lingkungan dengan tidak merusak lingkungan dan mengurangi fungsi utamanya. Pemanfaatan jasa lingkungan yang dimaksud adalah pemanfaatan air, wisata alam, perlindungan keanekaragaman hayati, penyelamatan dan perlindungan lingkungan serta penyerapan dan/atau penyimpanan karbon.

Sub DAS Way Betung mengalir melalui kawasan hutan Register 19 dan menjadi sumber air utama bagi Perusahaan Daerah Air Minum (PDAM) Kota Bandar Lampung, perusahaan Air Minum Dalam Kemasan (AMDK) dan sektor industri lainnya (Yuwono et al, 2011). Kontribusi Sub DAS Way Betung hulu sangat besar bagi kegiatan ekonomi di Kota Bandar Lampung karena segala aktivitas ekonomi dapat berjalan lancar apabila kondisi hulu DAS terjaga. Perubahan penggunaan hutan menjadi kebun campuran, lahan kering, permukiman dan semak menyebabkan penurunan kemampuan tanah dalam menginfiltrasikan curah hujan sehingga mengakibatkan kerusakan fungsi hidrologi DAS Way Betung (Yuwono et al, 2011). Kondisi ini akan sangat berpengaruh terhadap ketersediaan air bagi masyarakat Kota Bandar Lampung.

Berdasarkan kondisi tersebut, maka diperlukan penerapan pembayaran jasa lingkungan (PJL) antara pemanfaat jasa (buyer) maupun penyedia jasa (seller) untuk mendorong masyarakat agar bersedia melakukan upaya konservasi, selain itu masyarakat juga akan mendapatkan dana kompensasi karena telah melakukan upaya konservasi tersebut (Dasrizal et al, 2012). Beberapa potensi buyer tersebut adalah PDAM, perusahaan AMDK, taman wisata, hotel dan pemanfaat jasa air lainnya, sedangkan seller yang dimaksud adalah masyarakat yang berada di hulu Sub DAS Way Betung. Berdasarkan kondisi tersebut, maka perlu diketahui kesediaan menerima (Willingness to Accept) dari penyedia jasa (seller) agar mendapatkan harga yang sesuai dengan keinginan masyarakat. Dana kompensasi dari hasil negosiasi buyer dan seller tersebut akan diberikan kepada masyarakat hulu (seller) untuk biaya konservasi hutan agar dapat mengurangi kerusakan hutan yang mengakibatkan penurunan kualitas dan kuantitas air Sub DAS Way Betung. Berdasarkan kondisi tersebut, maka perlu adanya penelitian mengenai "Kesediaan menerima pembayaran jasa lingkungan air Sub DAS Way Betung hulu oleh masyarakat".

\section{METODE PENELITIAN}

\section{Lokasi dan Waktu Penelitian}

Penelitian ini dilaksanakan di Desa Talang Mulya Kecamatan Padang Cermin Kabupaten Pesawaran pada bulan Januari 2014. Lokasi penelitian merupakan bagian hulu dari Sub DAS Way Betung Hulu yang telah mengalami perubahan penggunaan lahan menjadi kebun campuran sebesar 52,2\% sehingga perlu adanya upaya konservasi dilokasi tersebut, lokasi ini merupakan kawasan hutan negara register 19. 


\section{Objek dan Alat Penelitian}

Objek pada penelitian ini adalah Masyarakat sekitar Sub DAS Way Betung hulu Register 19 Desa Talang Mulya Kecamatan Padang Cermin Pesawaran. Alat yang digunakan antara lain: alat tulis, kalkulator, komputer, panduan wawancara/kuisioner, dan kamera digital.

\section{Jenis dan Sumber Data}

Data yang digunakan dalam penelitian ini adalah data primer dan data sekunder. Data primer diperoleh dari wawancara langsung dengan responden. Data primer yang dibutuhkan meliputi: karakteristik responden, respon responden mengenai mekanisme pembayaran jasa lingkungan, respon responden mengenai estimasi nilai WTA responden. Data sekunder yang digunakan dalam penelitian ini diperoleh dari instansi pemerintah di lokasi penelitian. Data sekunder yang digunakan adalah data sosial demografis penduduk Desa Talang Mulya.

\section{Metode Pengambilan Sampel}

Pengambilan sampel dilakukan menggunakan metode purposive sampling. Desa Talang Mulya terdiri dari 3 (tiga) dusun yaitu dusun Talang Mulya dengan jumlah $142 \mathrm{KK}$, dusun Talang Baru dengan jumlah $71 \mathrm{KK}$ dan dusun Umbul Lapang dengan jumlah $125 \mathrm{KK}$, sehingga total jumlah kepala keluarga di Desa Talang Mulya adalah 338 KK (Profil Desa, 2013). Berdasarkan formula Slovin (Arikunto, 2011), maka didapatkan jumlah responden pada penelitian ini adalah

$$
\begin{array}{ll}
\mathrm{n}=\frac{N}{N(e)^{2}+1} & \begin{array}{l}
\text { Keterangan: } \\
\mathrm{n}=\text { jumlah sampel } \\
\mathrm{N}=\text { jumlah populasi } \\
\mathrm{e}=\text { batas error } 15 \% \\
1=\text { bilangan konstan }
\end{array} \\
\mathrm{n}=\frac{338}{338(15 \%)^{2}+1} & \\
\mathrm{n}=39,2794 \approx 39 \text { responden } &
\end{array}
$$

Mengingat Desa Talang Mulya terdiri dari 3 dusun yang jumlah sub populasinya tidak sama maka untuk mendapatkan sampel dari masing-masing dusun digunakan rumus (Walpole, 1993). Jumlah responden masing-masing dusun adalah 16 responden untuk Dusun Talang Mulya, 9 responden untuk Dusun Talang Baru dan 14 responden untuk Dusun Umbul Lapang.

$$
\begin{aligned}
& n \underline{i}=\frac{N \underline{i}}{N} \times n \\
& \text { Keterangan: } \\
& \mathrm{n} \quad \text { : Banyaknya sampel } \\
& \text { ni } \quad \text { : Banyaknya sampel ke-iz } \\
& \mathrm{N} \text { : Banyaknya populasi rumah tangga } \\
& \mathrm{Ni} \quad \text { : Banyaknya populasi ke-i } \\
& \text { I : Sub populasi }
\end{aligned}
$$

\section{Metode Pengolahan dan Analisis Data}

Data dan informasi yang diperoleh dalam penelitian akan dianalisis secara kualitatif dan kuantitatif dengan metode deskriptif dan model kuantitatif. Perhitungan dengan model analisa dilakukan dengan bantuan komputer. Proses pengolahan data dilakukan dengan program Minitab 16. Alasan pemilihan program ini adalah karena program ini mudah penggunaannya dan output yang dihasilkan cukup baik. 


\section{Analisis kesediaan menerima (WTA) masyarakat}

Cara untuk mengetahui nilai WTA masyarakat dalam penelitian ini adalah dengan menghitung nilai rataan WTA dan menghitung total WTA (Hanley and Spash, 1993).

a. Memperkirakan Nilai Rataan WTA

Dugaan nilai rataan WTA dihitung dengan rumus:

EWTA $=\frac{\sum_{t=0}^{n} W_{T A}}{n}$

dimana:

EWTA $=$ Dugaan nilai rataan WTA

$\mathrm{Xi} \quad=$ Jumlah tiap data

$\mathrm{n} \quad=$ Jumlah responden

$\mathrm{i}=$ Responden ke-I yang bersedia menerima dana kompensasi $(\mathrm{i}=1,2, \ldots, \mathrm{k})$

b. Menghitung Total WTA

Penjumlahan data merupakan proses dimana nilai tengah penawaran dikonversikan terhadap populasi yang dimaksud. Setelah menduga nilai tengah WTA maka dapat diduga nilai WTA dari masyarakat dengan rumus:

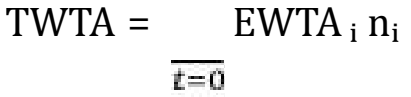

dimana:

TWTA $=$ Total WTA

EWTAi $=$ Nilai rata-rata WTA

ni $\quad=$ Jumlah pohon

I $\quad=$ Responden ke-I yang bersedia menerima dan kompensasi

$(\mathrm{i}=1,2, \ldots, \ldots \mathrm{k})$

\section{Analisis faktor-faktor yang mempengaruhi nilai WTA}

Untuk mengetahui faktor-faktor yang mempengaruhi nilai WTA dianalisis dengan model regresi bertahap (Stepwise regression) menggunakan Minitab 16. Model persamaannya adalah:

$$
\mathrm{Y}=\mathrm{B}_{0}+\mathrm{B}_{1} \mathrm{X}_{1}+\mathrm{B}_{2} \mathrm{X}_{2}+\mathrm{B}_{3} \mathrm{X}_{3}+\mathrm{B}_{4} \mathrm{X}_{4}+\mathrm{B}_{5} \mathrm{X}_{5}+\mathrm{B}_{6} \mathrm{X}_{6}+\mathrm{B}_{7} \mathrm{D}_{1}+\mathrm{B}_{8} \mathrm{D}_{2}
$$
dimana:

$\mathrm{Y}=$ Nilai WTA responden

$\mathrm{X}_{1} \quad=$ Tingkat pendidikan (tahun)

$\mathrm{X}_{2} \quad=$ Tingkat pendapatan rumah tangga (rupiah/bulan)

$\mathrm{X}_{3} \quad=$ Umur (tahun)

$\mathrm{X}_{4} \quad=$ Luas lahan garapan (ha)

$\mathrm{X}_{5} \quad=$ Lama tinggal responden dilokasi penelitian (tahun)

$\mathrm{X}_{6}=$ Jumlah anggota keluarga yang masih dalam tanggungan kepala keluarga (orang)

$\mathrm{D}_{1} \quad=$ Status garapan lahan (1 jika milik pribadi, 0 jika lainnya)

$\mathrm{D}_{2} \quad=$ Biaya konservasi (1 jika ada, 0 jika tidak ada)

\section{Analisis bentuk-bentuk insentif yang diinginkan masyarakat}

Identifikasi karakteristik responden serta persepsi responden terhadap bentuk-bentuk insentif yang diinginkan di lokasi penelitian menggunakan kuisioner/wawancara pertanyaan terbuka. Data yang didapatkan dari hasil wawancara akan dianalisis secara deskriptif kualitatif. 


\section{HASIL DAN PEMBAHASAN}

\section{Kesediaan masyarakat menerima pembayaran jasa lingkungan air}

Kesediaan dan ketidaksediaan responden dalam menerima nilai pembayaran jasa lingkungan air perlu diidentifikasi sebelum melakukan analisis Willingness to accept (WTA). Sebanyak 39 responden yang diwawancara mengenai kesediaan atau ketidaksediaan menerima pembayaran jasa lingkungan air, terdapat 97,4\% responden (38 orang) bersedia menerima dan 2,6\% responden ( 1 orang) tidak bersedia menerima pembayaran.

Hampir seluruh responden bersedia menerima pembayaran jasa lingkungan air, alasannya adalah perlu adanya upaya konservasi yang dilakukan di kawasan hutan register 19 sehingga dana kompensasi yang diberikan kepada masyarakat akan membantu masyarakat dalam menjaga tegakan pohon yang ada di lahan miliknya (Bac et al, 2014). Terdapat 1 (satu) orang responden yang tidak bersedia menerima pembayaran jasa lingkungan air. Alasan responden tersebut menolak pembayaran jasa lingkungan air adalah responden merasa bahwa melakukan upaya konservasi hutan adalah suatu kewajiban masyarakat sehingga tidak perlu diberikan insentif agar mau melakukan upaya konservasi tersebut.

Berdasarkan hasil wawancara dengan responden didapatkan nilai pembayaran jasa lingkungan air yang bersedia diterima responden dengan nilai yang bervariasi mulai dari $\mathrm{Rp}$ 5.000,00 hingga Rp 10.000,00. Frekuensi nilai WTA masing-masing responden dapat dilihat pada tabel 1.

Tabel 1. Besaran WTA Responden

\begin{tabular}{ccccc}
\hline No & $\begin{array}{c}\text { Nilai WTA } \\
\text { (RP/Pohon/Tahun) }\end{array}$ & Frekuensi (Orang) & Frekuensi Relatif & $\begin{array}{c}\text { Mean WTA (Rp/pohon/ } \\
\text { tahun) }\end{array}$ \\
\hline 1 & 5.500 & 2 & 0,05 & 289,47 \\
2 & 6.500 & 7 & 0,18 & $1.197,37$ \\
3 & 7.500 & 7 & 0,18 & $1.381,58$ \\
4 & 8.500 & 6 & 0,16 & $1.342,11$ \\
5 & 9.500 & 3 & 0,08 & 750,00 \\
6 & 10.500 & 13 & 0,34 & $3.592,11$ \\
\hline & Total & $\mathbf{3 8}$ & $\mathbf{1 , 0 0}$ & $\mathbf{8 . 5 5 2 , 6 3}$ \\
\hline
\end{tabular}

Sumber: Data Primer Diolah, 2014

\section{Analisis nilai rataan WTA}

Berdasarkan tabel 1 dapat diketahui bahwa kesediaan menerima pembayaran jasa lingkungan air dari responden yang terendah adalah sebesar Rp 5.500,00 per pohon per tahun dengan frekuensi responden sebanyak 2 orang, sedangkan kesediaan menerima pembayaran jasa lingkungan air tertinggi adalah sebesar Rp 10.500,00 per pohon per tahun dengan frekuensi responden sebanyak 13 orang. Sebagian besar responden merasa bahwa biaya untuk pemeliharaan lahan kebun campuran cukup besar sehingga nilai WTA yang diinginkan responden tersebut menjadi besar, sedangkan beberapa responden merasa bahwa upaya konservasi lahan merupakan tanggung jawab bersama sehingga responden tidak ingin memberatkan pembeli jasa lingkungan air (buyer).

Perhitungan terhadap dugaan nilai rataan WTA (tabel 1) menghasilkan nilai sebesar Rp $8.552,63$ per pohon per tahun. Nilai WTA tersebut lebih besar jika dibandingkan dengan nilai WTA di DAS Cidanau yaitu sebesar Rp 5.056,98 per pohon per tahun dan nilai WTA di DAS Brantas yaitu sebesar Rp 8.265,00 per pohon per tahun (Triani 2009 dan Antika 2011). 


\section{Analisis total WTA}

Berdasarkan data gabungan kelompok tani Desa Talang Mulya jumlah pohon total di kebun campuran masyarakat adalah sebanyak 1.462 pohon. Pohon yang dimaksud dalam penelitian ini adalah tanaman berkayu yang tingginya lebih dari 5 meter dan berdiameter $\geq 20$ $\mathrm{cm}$, tidak termasuk tanaman MPTS (Multi Purpose Tree Species) (Indriyanto, 2008). Jenis pohon yang mendominasi dikebun campuran masyarakat diantaranya adalah medang, merambung, cempaka, sonokeling dan mahoni. Lahan kebun campuran yang dikelola oleh masyarakat merupakan kawasan Taman Hutan Raya Wan Abdurahman Register 19.

Hasil perhitungan nilai total WTA responden diperoleh dari perkalian nilai rata-rata WTA responden dengan jumlah pohon total yang terdapat pada lahan kebun campuran masyarakat. Berdasarkan perhitungan diperoleh nilai total WTA (TWTA) adalah sebesar Rp 12.503.945,06 per tahun. Nilai tersebut merupakan nilai total kesediaan menerima pembayaran jasa lingkungan air Desa Talang Mulya.

Kondisi lahan masyarakat yang didominasi tanaman perkebunan dan tanaman MPTS belum bisa dikatakan lestari karena dari fungsi ekologis tanaman kayu yang lebih baik untuk konservasi, sehingga perlu adanya penanaman tanaman kayu. Dalam penerapan pembayaran jasa lingkungan dana insentif yang diberikan kepada penyedia jasa lingkungan harus sesuai dengan kondisi tanaman yang ada di lahan masyarakat. Tanaman yang dapat diikutsertakan dalam program PJL ini harus sudah mencapai fase pohon atau tanaman dengan tinggi minimal 5 meter dan diameter batang $20 \mathrm{~cm}$.

\section{Faktor-faktor yang mempengaruhi nilai WTA}

Analisis faktor-faktor yang mempengaruhi WTA dilakukan dengan menggunakan analisis regresi bertahap (Stepwise regression). Variabel tidak bebasnya (dependen) adalah nilai WTA responden, sedangkan variabel bebasnya (independen) terdiri dari tingkat pendidikan $\left(\mathrm{X}_{1}\right)$ tingkat pendapatan rumah tangga $\left(\mathrm{X}_{2}\right)$, umur responden $\left(\mathrm{X}_{3}\right)$, luas lahan garapan $\left(\mathrm{X}_{4}\right)$, lama tinggal responden $\left(\mathrm{X}_{5}\right)$, jumlah tanggungan responden $\left(\mathrm{X}_{6}\right)$, status garapan lahan $\left(\mathrm{D}_{1}\right)$ dan biaya konservasi lahan $\left(\mathrm{D}_{2}\right)$. Hasil analisis nilai WTA responden dapat dilihat pada tabel 2.

Tabel. 2 Hasil analisis nilai WTA responden

\begin{tabular}{lcccc}
\hline \multicolumn{1}{c}{ Variabel } & Koefisien & P & VIF & Keterangan \\
\hline Constant & 9,4334 & 0,000 & & \\
PDD & $-1,53427$ & $\mathbf{0 , 0 0 0}$ & 2,93843 & Nyata* $^{*}$ \\
UMUR & $-0,14631$ & $\mathbf{0 , 0 0 0}$ & 3,05244 & Nyata* \\
SGL & 4,53378 & $\mathbf{0 , 0 1 0}$ & 1,07508 & Nyata* \\
\hline R-Squares & & $\mathbf{9 7 , 0 6} \%$ & \\
Adjusted R Squares & & $\mathbf{9 6 , 8 1 ~ \%}$ & & \\
\hline
\end{tabular}

Keterangan: * nyata pada taraf $(\alpha) 0,05$

Berdasarkan hasil pengolahan data diperoleh nilai keragaman sebesar 96,81\% (tabel 2). Nilai ini menunjukan bahwa keragaman WTA responden dapat dijelaskan oleh model, sisanya yaitu sebesar 3,19\% dijelaskan oleh variabel lain diluar model. Model regresi yang sesuai harus memenuhi beberapa asumsi yaitu kenormalan sisaan, kehomogenan ragam (homoscesdasticity), kebebasan sisaan (autocorrelation) dan bebas dari multikolinearitas.

Kenormalan sisaan dapat diketahui dengan uji Kolmogorov Smornov, hasil yang didapatkan menunjukan P-value berada diatas 0,05, maka dapat disimpulkan bahwa memenuhi asumsi sisaan menyebar normal. Pemeriksaaan asumsi untuk menguji masalah multikolinearitas didasarkan pada nilai VIF. Hasil yang diperoleh (tabel 2) menunjukan bahwa nilai VIF masing-masing variabel bebas memiliki nilai kurang dari sepuluh $(\mathrm{VIF}<10)$. 
Hal ini menandakan bahwa tidak terjadi pelanggaran multikolinearitas. Pemeriksaan kehomogenan ragam (homoscesdasticity) dapat diketahui dengan Uji Glejser. Hasil dari uji ini menunjukan bahwa P-value berada diatas taraf nyata $(\alpha) 0,05$, maka tidak terdapat pelanggaran asumsi homoskedastisitas. Model yang dihasilkan dari analisis ini adalah:

WTA $=9,43-1,53427 \mathrm{X}_{1}-0,146309 \mathrm{X}_{3}+4,53378 \mathrm{D}_{1}$

Keterangan:

$$
\mathrm{R}^{2}=97,06 \% \text { Adjusted } \mathrm{R}^{2}=96,81 \%
$$

WTA : Nilai WTA responden (Rp)

$\mathrm{X}_{1} \quad$ : Tingkat pendidikan (Tahun)

$\mathrm{X}_{3} \quad$ : Umur (Tahun)

$\mathrm{D}_{1} \quad$ : Status garapan lahan

Berdasarkan analisis regresi bertahap variabel yang berpengaruh nyata terhadap nilai WTA responden yaitu sebagai berikut:

1. Tingkat pendidikan $\left(\mathrm{X}_{1}\right)$

Variabel tingkat pendidikan memiliki P-value 0,000 yang artinya bahwa variabel ini berpengaruh nyata terhadap nilai WTA responden dengan taraf nyata $\alpha 0,05(5 \%)$. Nilai koefisien variabel tingkat pendidikan memiliki tanda (-) dengan nilai sebesar 1,53427, hal ini berarti jika tingkat pendidikan responden meningkat satu satuan (tahun) maka nilai WTA responden akan menurun sebesar Rp 1,53427.

Semakin tinggi tingkat pendidikan responden maka akan semakin rendah nilai WTA yang ditawarkan responden karena semakin tinggi tingkat pendidikan seseorang maka akan semakin banyak pula pengetahuan yang dimilikinya mengenai pentingnya upaya konservasi hutan (Antika, 2011). Tingkat pengetahuan responden yang berbeda-beda sehingga pendapat yang diungkapkan dalam menanggapi sesuatu hal pun berbeda, hal ini yang menyebabkan variabel ini berpengaruh nyata terhadap model.

2. $\operatorname{Umur}\left(\mathrm{X}_{3}\right)$

Variabel umur memiliki P-value 0,000 yang artinya bahwa variabel ini berpengaruh nyata terhadap nilai WTA responden dengan taraf nyata $\alpha 0,05(5 \%)$. Nilai koefisien variabel umur memiliki tanda (-) dengan nilai sebesar 0,14631 , hal ini berarti jika umur responden meningkat satu satuan (tahun) maka nilai WTA responden akan menurun sebesar $\quad \operatorname{Rp} 0,14631$.

Semakin tua umur seseorang tetapi masih dalam rentang usia produktif yaitu 15 tahun sampai 64 tahun maka tingkat kedewasaan seseorang akan semakin baik dalam mengambil keputusan (Febriani, 2008). Pada saat usia lebih dari 64 tahun maka tingkat produktifitasnya akan menurun karena memasuki usia lanjut, sehingga semakin tua usia responden tetapi dalam batas usia produktif akan semakin rendah nilai WTA yang ditawarkan.

3. Status garapan lahan $\left(\mathrm{D}_{1}\right)$

Variabel status garapan lahan memiliki P-value 0,010 yang artinya variabel ini berpengaruh nyata terhadap nilai WTA pada taraf nyata $\alpha 0,05(5 \%)$. Variabel ini memiliki koefisien bertanda (+) dengan nilai sebesar 4,53378, artinya jika lahan yang dikelola responden adalah lahan milik pribadi maka nilai WTA yang ditawarkan akan meningkat sebesar Rp 4,53378. Jika lahan garapan merupakan lahan garapan pribadi maka rasa kepemilikan responden terhadap lahan tersebut akan lebih tinggi dibandingkan jika lahan garapan merupakan sistem bagi hasil atau sewa, sehingga nilai WTA responden meningkat jika dilahan garapan pribadi. 
Sedangkan variabel yang tidak berpengaruh nyata terhadap nilai WTA adalah tingkat pendapatan $\left(\mathrm{X}_{2}\right)$, luas lahan garapan $\left(\mathrm{X}_{4}\right)$, lama tinggal responden $\left(\mathrm{X}_{5}\right)$, jumlah tanggungan $\mathrm{X}_{6}$ ) dan biaya konservasi $\left(\mathrm{D}_{2}\right)$. Variabel tingkat pendapatan tidak berpengaruh nyata karena pendapatan responden tidak berasal dari sektor pertanian saja, tetapi banyak responden yang mempunyai mata pencaharian lain seperti dagang, buruh bangunan dan lainnya. Variabel luas lahan tidak berpengaruh nyata karena responden menganggap lahan yang dikelola adalah lahan milik negara sehingga responden merasa tidak berhak untuk menawarkan nilai WTA yang besar. Variabel lama tinggal tidak berpengaruh nyata karena responden yang lebih lama tinggal di desa ini telah menyadari pentingnya kelestarian hutan. Variabel jumlah tanggungan tidak berpengaruh nyata karena jumlah pengeluaran rumah tangga dengan tanggungan lebih banyak tidak terlalu jauh berbeda dengan pengeluaran rumah tangga dengan jumlah tanggungan sedikit. Variabel biaya konservasi tidak berpengaruh nyata terhadap model karena sebagian responden memelihara lahan dengan tenaga sendiri sehingga tidak mengeluarkan biaya untuk pemeliharaan lahan.

\section{Bentuk-bentuk insentif yang diinginkan masyarakat}

Berdasarkan wawancara dengan responden didapatkan empat (4) bentuk-bentuk insentif yang diinginkan masyarakat yaitu dalam bentuk uang tunai yaitu sebesar $54 \%$ responden, hal tersebut dikarenakan responden merasa jika dalam bentuk uang tunai maka responden dapat langsung menggunakan dana insentif tersebut untuk biaya pemeliharaan lahan serta dapat meringankan kebutuhan hidup. Responden menilai bahwa jangka panen tanaman kayu lebih lama dibandingkan tanaman semusim sehingga dana insentif dapat digunakan untuk memenuhi kebutuhan jangka pendek. Bentuk insentif yang kedua adalah dalam bentuk pembangunan pedesaan yaitu sebesar $36 \%$ responden, hal ini dikarenakan responden menganggap bahwa keadaan desa masih membutuhkan pembangunan infrastruktur yang antara lain berupa jalan, mushala, tempat mengaji, sekolah dan bangunan-bangunan lainnya yang dapat digunakan untuk kepentingan bersama.

Bentuk insentif yang ketiga adalah berupa bantuan bibit dan pupuk yaitu sebesar 5\% responden, responden beralasan bahwa dalam melakukan upaya konservasi hutan diperlukan bibit-bibit pohon yang berkualitas agar menghasilkan tanaman yang dapat berfungsi menjaga tata air di hutan serta bantuan pupuk agar pertumbuhan tanaman semakin baik. Tanaman yang mendominasi di kebun campuran masyarakat adalah kopi, kakao, tangkil, durian, cengkeh dan kemiri. Artinya perlu adanya penanaman pohon kayu keras yang dapat berfungsi sebagai penyimpan air hujan didalam tanah agar DAS Way Betung tetap lestari. Sedangkan bentuk insentif yang terakhir adalah berupa bantuan hewan ternak yaitu sebesar 5\% responden, hewan ternak yang dimaksud responden adalah sapi. Alasannya adalah nilai ekonomi yang tinggi dari sapi sehingga dapat membantu penghasilan masyarakat, selain itu kondisi di Desa Talang Mulya yang banyak terdapat rumput sehingga dapat dijadikan pakan bagi sapi.

\section{KESIMPULAN}

Berdasarkan hasil dan pembahasan penelitian ini, maka dapat disimpulkan:

1. Nilai dugaan rataan WTA Desa Talang Mulya adalah Rp 8.552,63 per pohon per tahun,. Sedangkan nilai total WTA Desa Talang Mulya sebesar Rp 12.503.945,06 per tahun.

2. Faktor-faktor yang berpengaruh nyata terhadap nilai WTA yaitu tingkat pendidikan, umur dan status garapan lahan.

3. Bentuk-bentuk insentif yang diinginkan, berupa uang tunai, pembangunan pedesaan, bantuan bibit dan pupuk dan bantuan hewan ternak. 


\section{DAFTAR PUSTAKA}

Antika, A.P. 2011. Analisis willingness to accept masyarakat terhadap pembayaran jasa lingkungan DAS Brantas. Skripsi. IPB. Bogor.

Arikunto, S. 2011. Prosedur Penelitian Suatu Pendekatan Praktik. Buku. Rineka Cipta. Jakarta.

Bac D.U, Catacutan D.C and Ha H.M. 2014. Importance of national policy and local interpretation in designingpayment for forest environmental services scheme for the ta leng river basin in Northeast Vietnam. Journal Environment and Natural Resources Research. 4(1): 39-53p, 2014.

Dasrizal, Ansofino, Juita E and Jolianis. 2012. Model sistem pembayaran jasa lingkungan dalam kaitannya dengan konservasi sumber daya air dan lahan. Jurnal Program Studi Pendidikan Ekonomi STKIP PGRI Sumatera Barat. 1(1), 2012.

Febriani, N. 2008. Kajian konservasi lahan di hulu das citarum dalam upaya mendukung pengembangan wilayah berbasis sumberdaya alam yang berkelanjutan. Thesis. IPB. Bogor.

Hanley, N. and C.L. Spash. 1993. Cost Benefit Analysis and The Environment. Book. Departement of Economics University of Stirling Scotland.

Pemerintah Republik Indonesia. 2008. Peraturan Pemerintah Republik Indonesia Nomor 3 Tahun 2008 tentang Tata Hutan dan Penyusunan Rencana Pengelolaan Hutan, serta Pemanfaatan Hutan . Jakarta.

Profil Desa. 2013. Rencana pembangunan jangka menengah Desa Talang Mulya. Talang Mulya.

Triani, A. 2009. Analisis willingness to accept masyarakat terhadap pembayaran jasa lingkungan DAS Cidanau. Skripsi. IPB. Bogor.

Walpole, R. 1993. Pengantar Statistika. Buku. PT. Gramedia Pustaka Utama. Jakarta.

Yuwono S.B, Sinukaban N, Murtilaksono K and Sanim B. 2011. Land use planning of Way Betung watershed for sustainable water resources development of Bandar Lampung City. Journal Tropical Soils. 16(1): 77-84p, 2011. 
Vol. 3 No. I, Januari 2015 (21-30)

Halaman ini sengaja dikosongkan 